\title{
THE DISCOVERY AND PHARMACOLOGY OF CYCLOPROPANE ${ }^{1}$
}

\author{
G. H. W. LuCAS ${ }^{2}$
}

IT wAS over thirty years ago, on November 22, 1928, that 1 prepared. in the laboratory of the Department of Pharmacology of the University of Toronto, the first sample of cyclopropane ever to be used for anaesthetic experiments on laboratory animals. I trust the reader will bear with me, however, if I first go back a few years prior to that date to show how previous research in the Department led to the discovery of cyclopropane. The data I shall present may be gleaned piecemeal from the various departmental publications prior to 1928, but hitherto no one has brought them together in one paper.

I first became acquainted with Professor Velyien E. Henderson, several years before I joined his Department, through my efforts to discover the growthpromoting factor in yeast, under Professor W. Lash Miller of the Department of Chemistry. Certain feeding experiments on animals were carried out in the Department of Pharmacology. Later I served as biochemist for the late Sir Frederick Banting, who had his laboratory in Professor Henderson's Department. Because of this I was aware of some of the research in progress in anaesthesia and when, in 1927, Professor Henderson offered me the opportunity of joining in this research, I accepted without hesitation.

The story from 1927 on involves four persons - the late Professor Velyien E. Henderson, Dr. W. Easson Brown, Mr. Allan Brock, and myself. Mr. Brock, who at the time was laboratory assistant and machinist in the Department, assisted in operations on the animals and in the design and manufacture of any new and essential apparatus.

At least 35 papers dealing with anaesthetics and anaesthesia have been published by members of the Staff in Pharmacology. A worldwide quest for a general anaesthetic more suitable than ether or chloroform or nitrous oxide reached its peak about 1923. The earliest investigations in this field were undertaken by Paul Bert in 1878 on nitrous oxide, but little attention had been paid to his results.

Ethylene was under serious investigation in various laboratories on the North American continent about 1920, and in Toronto, Dr. W. Easson Brown became interested in it. He was aware that in 72 per cent concentration it was not toxic to animals; in August, 1922, he anaesthetized rabbits and mice with 80 per cent ethylene and 20 per cent oxygen. A paper on this subject, which he read before the Toronto Academy of Medicine on February 20, 1923, was published in the March 7 issue of the Canadian Medical Association Journal of that year (1). A week later A. B. Luckhardt and J. B. Carter published a report of their work on the same gas in the Journal of the American Medical Association (2). In a later

'Presented at the Annual Meeting, Canadian Anaesthetists' Society, May 6, 1959.

2Department of Pharmacology, University of Toronto. 
publication, on May 19 of the same year, they reported that they had conducted 106 operations in hospitals, using this gas as a general anaesthetic. In the American literature, Brown is not given credit for the earliest publication on the anaesthetic value of ethylene in laboratory animals, possibly because he published his results in a Canadian journal.

Brown meanwhile continued his experimental work on animals in co-operation with Dr. Henderson and extended it to include anaesthetization of some members of the laboratory staff. He used it in several operations on human patients. The fact that ethylene could be used in concentrations of 80 per cent or over for satisfactory anaesthesia, and had been used extensively by Luckhardt, did not satisfy Dr. Brown and Professor Henderson. From the study of the narcotic properties of alcohol, it was postulated that propylene would be a more potent gas than ethylene and its preparation was begun in the laboratory early in 1924 . In July of that year Brown reported in the Journal of Pharmacology and Experimental Therapeutics (3) that propylene had definite anaesthetic properties and would induce anaesthesia in concentrations as low as 37 per cent in air or oxygen. Anaesthesia, he asserted, could be maintained in concentrations from 20 to 31 per cent in oxygen; in concentrations of 65 per cent or over it was considered toxic.

A chemical engineer, Mr. L. J. Bonham, working on a special grant in the Department of Pharmacology, succeeded in making a very pure sample of propylene and reported his findings in the February, 1925, issue of the Journal of the American Pharmaceutical Association (4). Samples of the gas thus made were excellent for anaesthesia on experimental animals. However, when it was tanked in steel alloy tanks, toxic materials developed in it; these were not present in the original gas prepared in the laboratory. As no means were found to account for this unexpected toxic action, or to remove the toxic product, anaesthetic research with this gas came to a standstill.

. It was at this juncture that I joined the staff of the Department of Pharmacology. As I reviewed the literature on anaesthesia and became more famtliar with the work of Brown and Henderson on propylene, it was apparent that the serious metabolic changes occurring during anaesthesia were in part due anoxaemia. We decided to direct our attention to the work of Paul Bert (5) on nitrous oxide administered with oxygen under pressure. He had maintained that satisfactory anaesthesia could be attained with nitrous oxide-oxygen mixtures under pressure greater than that of the atmosphere. He pointed out that, by increasing the pressure to $1 \frac{1}{4}$ atmospheres in a nitrous oxide 80 per cent-oxygen 20 per cent mixture, the partial pressures of the nitrous oxide would be the same as that of pure nitrous oxide. According to Henry's Law of the solution of gases, a patient breathing this mixture under pressure would have in his blood as much nitrous oxide as he would have when he breathed pure nitrous oxide. Bert reported successful surgery with this anaesthetic mixture.

Over a year was spent investigating the anaesthetic value of nitrous oxideoxygen mixtures under pressure. We experienced much difficulty in designing a suitable tank in which to anaesthetize laboratory animals (rabbits, cats, and rats). After several tanks burst under pressure, a satisfactory one was made from steel tubing heavily reinforced. 
Despite the fact that pressures up to 2 atmospheres were employed and partial pressures of nitrous oxide were $1 \frac{1}{2}$ times that of pure nitrous oxide when inhaled, a satisfactory state of deep surgical anaesthesia was not reached. Animals when stimulated could move about in the cage. Anaesthesia could be secured at these high partial pressures of nitrous oxide only when the partial pressure of oxygen was so low that anoxaemia was present. ${ }^{3}$ Thus ended another anaesthetic venture. We seemed to have come to a dead end.

During the researches on nitrous oxide and oxygen under pressure, little attention had been paid to the tank of propylene, prepared by E. R. Squibb and Sons several years previously, which had developed peculiar toxic products. Professor Henderson now drew my attention to this unsuccessful experiment and suggested that I give the matter some attention to learn, if possible, what substance could have formed in the tanked gas. While searching the literature, I found that cyclopropane, which is an isomer of propylene, might be formed during any chemical reaction in which propylene was prepared. I performed some qualitative analyses on the sample of toxic gas and came to the conclusion that some cyclopropane was present. I suggested that this gas might be the toxic mi.terial; I could not find any data in the literature regarding its toxic effects when inhaled. Professor Henderson therefore decided that I should prepare cyclopropane, employing the method published by Wilstätter in which trimethylenebromide was reduced by zinc to cyclopropane in the presence of alcohol and traces of water. Since we suspected the gas was poișonous, it was approached with a great deal of care.

According to my notebook, the first sample of cyclopropane was prepared for anaesthesia on November 22, 1928 (Fig. 1). It was employed to anaesthetize cats in a manner similar to that used for propylene. Needless to say, the stage was set for anaesthetic experiments jon this gas because much apparatus had been designed for research on ethylene and propylene. To our amazement, the cyclopropane was not toxic but anaesthetized animals in concentrations lower than those observed for any other anaesthetic gas. The animals recovered rapidly. It was evident that cyclopropane was a gas which invited further invest tration.

I shall not burden you with minor details of the ensuing experiments. However, it is interesting to note that, as cyclopropane was solube in sulphuric acid, it was relatively easy to measure concentrations in any mixture employed for anaesthesia. An impurity in the gas, probably saturated hydrocarbons, was obtained in quantity by dissolving out the cyclopropane in sulphuric acid and leaving this gas as a residue. When this residue was tested, it had no anaesthetic value. Experiments with cyclopropane showed that it was anaesthetic in a concentration of approximately 12 per cent in oxygen and that the concentration could be increased up to 30 per cent or so without causing serious toxic effects on the heart, but respiration at higher concentrations was somewhat shallow. Repeated administration of the gas to animals did not cause toxic effects $(7,8)$. The changes in metabolism were measured; these were practically nil. The gas was

${ }^{3}$ Although these results were published in the Journal of Pharmacology and Experimental Therapeutics in August, 1927 (6), same textbooks still state that nitrous oxide-oxygon mixtures under pressure give satisfactory anaesthesia. 


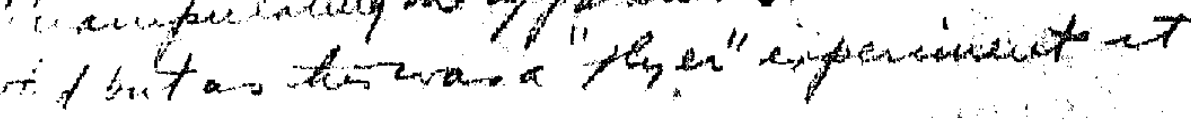

$\therefore \quad 1=\ldots$ a e.t.

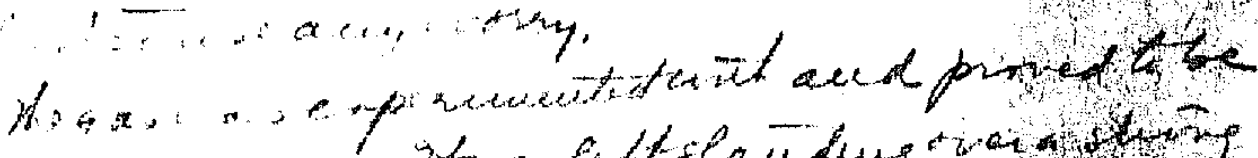

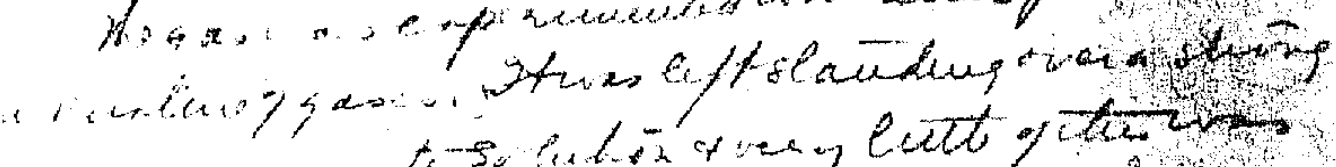

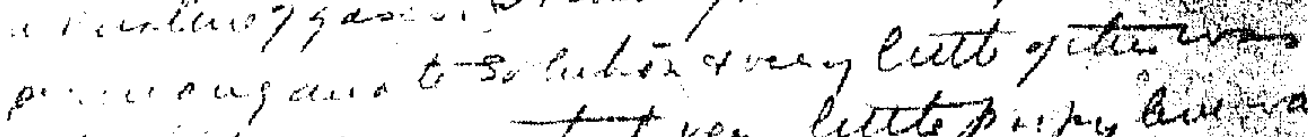

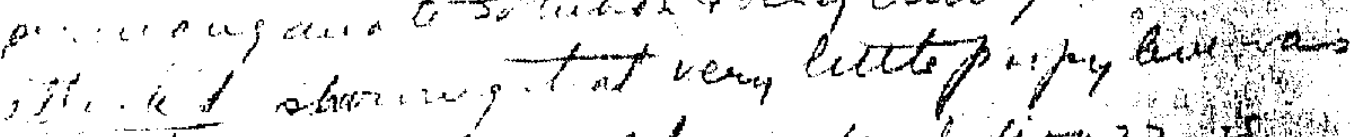

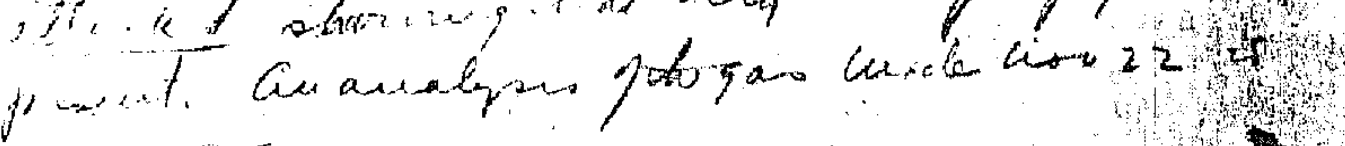

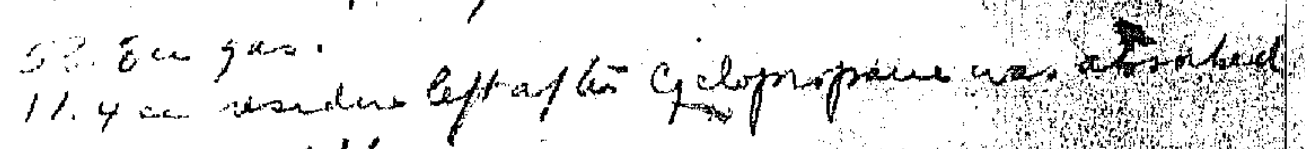

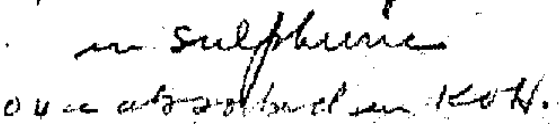

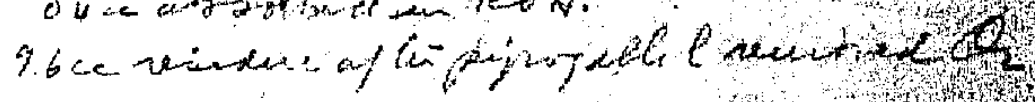

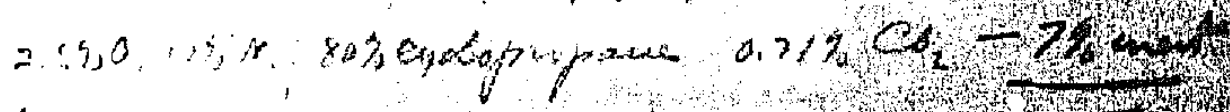

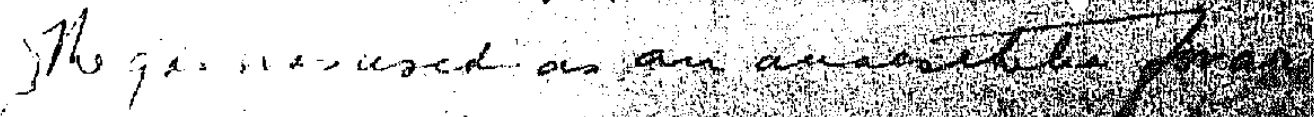

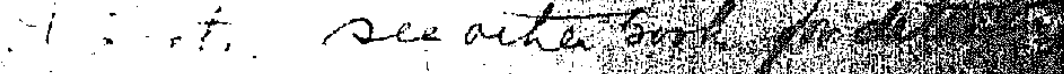


found to be explosive in air or in oxygen in anaesthetic concentrations the onl water partition coefficient was determined for 1 t

Professor Henderson reported briefly the results of our discovery at the Annual Meeting of the Canadian Medical Association June 211929 (9) and in October of the same year I presented a longer paper at the Annual Congress of Anaesthetists in Chicago (10) At that time we had not experimented on humans because we felt the gas was too impure

The gas was subsequently prepared in pure state and the crucial test was performed namely tanking it under pressure in steel alloy tanks to ascertain whether or not inpurities formed in the gas as they did with propylene About $120 \mathrm{~L}$ of gas were manufactured purified and then liquefied by being passed through a glass cooling coil immersed in liquid air A small steel tank fitted with a connection for an anaesthetic machine and with a small removable plug was also cooled in liquid aym( $F_{1 g}$ 2) The liquid cyclopropane was poured into the steel tank and the plug was inserted and secured The tank was then permitted to remain in the laboritory at room temperature for about one month As experments on anmmals showed that the gas had not become toxic on standing we proceeded to the experiments on humans

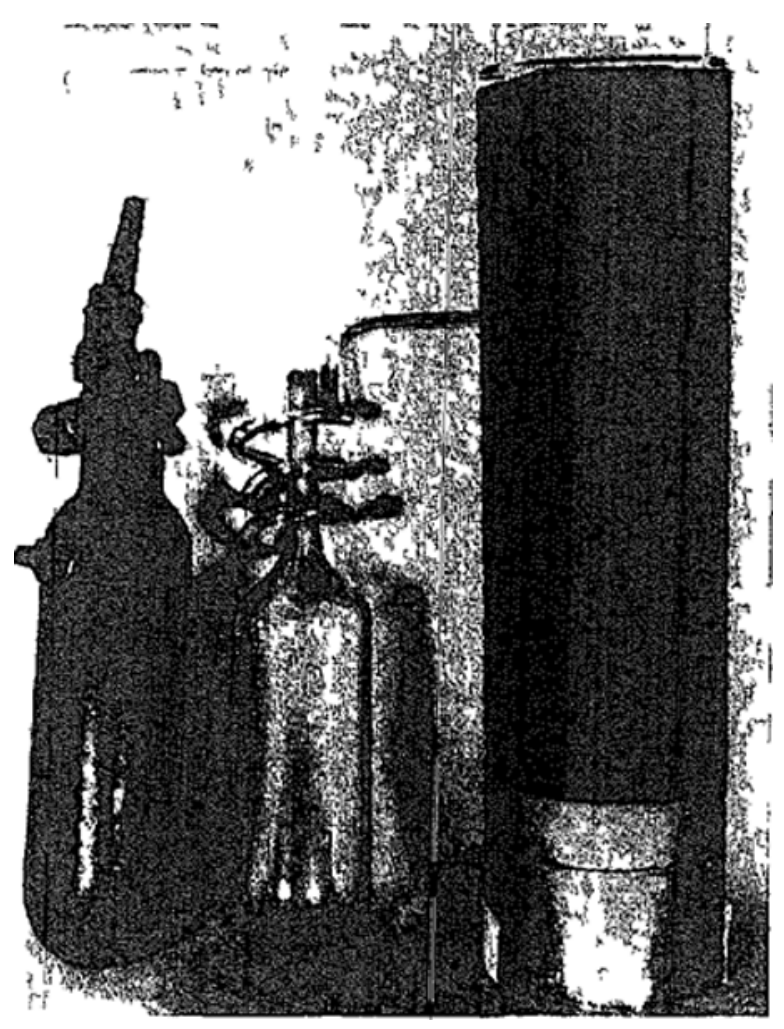

Figure 2 The equipment first fised to liquify and the first tank used to contain cyclopropane for anaesthetic purposes 
Dr. W. Easson Brown had not bcen actively engaged in research on cyclopropane up to this date; he had discussed the experiments with Professor Henderson and me and we had agreed that his contribution would be mainly in the human experimentation. He was the first doctor in the world to administer cyclopropane in anaesthetic concentrations to humans, the first patient being Professor Velyien E. Henderson. At this first sitting, my task, as the analyst, was to check concentrations of the administered cyclopropane rapidly. $\mathrm{Mr}$. Brock regulated the flow of gas and Dr. Brown looked after his patient. Both induction and recovery were rapid following a short anaesthetic. No ill effects followed. Dr. Brown then anaesthetized several members of the staff, myself included. We knew then that the gas was ready for experimental use in the hospital; we had at hand all the necessary equipment for measuring and controlling the anaesthetic concentrations.

At this particular time our luck changed. Three deaths which had occurred in Toronto in a relatively short period from the administration of ethyl chloride to patients gave rise to considerable newspaper publicity. Dr. Brown, who was on the anaesthetic staff of the Toronto General Hospital, begged the privilege of administering some of our sample of non-toxic cyclopropane to a patient, even for a short surgical procedure. A demonstration was put on one evening in our laboratory when Dr. Brown anaesthetized Dr. Frederick Banting before a number of physicians, but this was of no avail. Dr. Samuel Johnston, Head of the Department of Anaesthesia, who was present, observed the effects of cyclopropane, but in view of the unfortunate ethyl chloride deaths he forbade the use of cyclopropane in the hospital. It remained for others at a later date to investigate the anaesthetic value of this gas in surgery.

In Toronto we experimented with laboratory animals using commercial cyclopropane supplied by E. R. Squibb and Sons (Fig. 3) and then turned attention to cyclopropane derivatives, hoping to discover one which would be an ideal liquid anaesthetic at room temperature, would have a boiling point about that of chloroform and could be administered by means of a mask. I prepared several chlor-derivatives of cyclopropane and also ethyl-and methyl-derivatives. None of these, however, to my mind was of value. Either they were too toxic or the boiling point was too high. I decided to abandon research in anaesthesia.

Professor Henderson continued a more extensive study of cyclopropane derivatives but found nothing of anaesthetic value. A chemist, Mr. A. H. R. Smith (11), was engaged to investigate the old tanked propylene and discovered hexenes in it; these were extremely toxic to laboratory animals. It would appear that Professor Henderson persevered until he had established the toxic component of the tanked propylene. It was fortunate for both of us that, when we began our experiments in 1928 , I had come to the conclusion that cyclopropane was a constituent of the tanked propylene.

The stage for further cyclopropane experimentation was now moved to Wisconsin. Dr. Ralph M. Waters, in the Wisconsin General Hospital at Madison, had heard my paper on cyclopropane in Chicago and was very interested in the new anaesthetic. He and Professor Henderson were close friends and judging by a letter written to Professor Henderson in August, 1930, Professor Henderson 


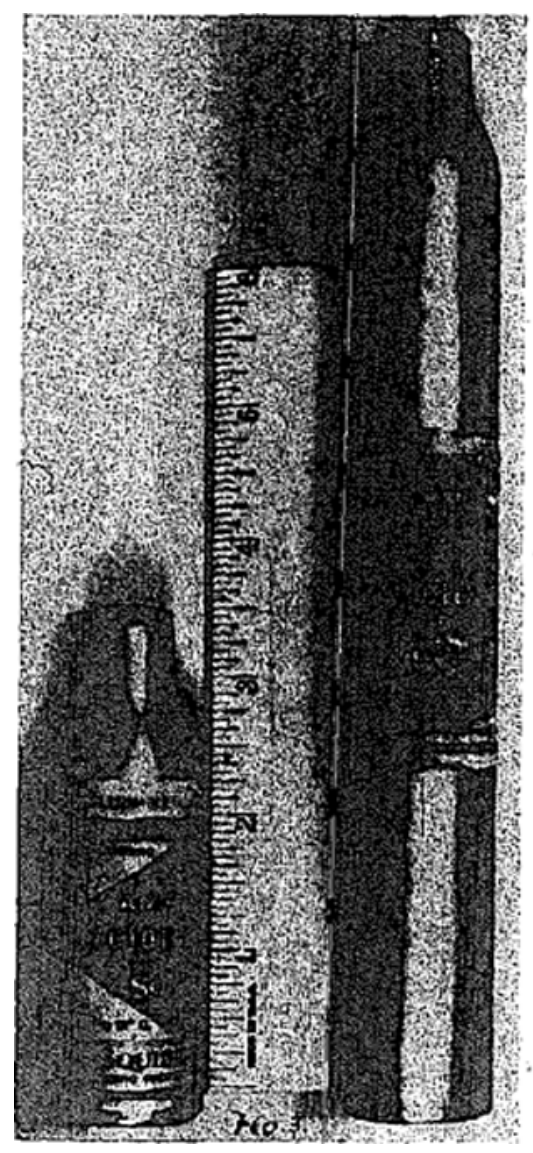

Figure 3. The first commercial "tanks" of cyclopropane supplied by E. R. Squibb \& Sons.

must have encouraged Dr. Waters tơ use cyclopropane as an anaesthetic on patients, following our failure to try it in the Ioronto General Hospital. After Professor Henderson's death I was asked to examine departmental files and records and discovered Dr. Waters' letter to Prolessor Henderson dated August 20, 1930 (Fig. 4). In this letter he stated that he had sccured a small tank of cyclopropane from the Ohio Chemical Company and, after testing it on a dog, he had used it in the hospital on three patients. One operation was a simple appendectomy (35 min.; Fig. 5); one an inguinal hernia ( 40 min.; Fig. 6); a third on a fat wornan, her tenth operation, for the removal of a gall bladder previously drained and the repair of a recurrent inguinal hernia ( $1 \mathrm{hr} .28 \mathrm{~min}$. Fig. 7). Dr. Waters had included a copy of the operating room charts for each patient. Analysis showed that about 40 per cent cyclopropane was essential for anaesthesia.

He states in his letter, "I believe that further investigations on this are distinctly indicated because the thing which inaeschesia needs more than anything 
Profeasor 7 . Hendorson

Uniroraty of Taronto

Ontex10, Cenede

Dane Dootor Honderaon:

Lt your suggemtion. I seourbd from the Ohio Chomian

Company a small tak containing tan galions ot Gyolopropane. Thio, by means ot the absorber tootalque, I found sufticient to anesthetian one dog, forty minutos, and being then wetiafiod that I neod not berm tho pationt:. I have usou the romainder of the hank for threo oomplete di-ni-

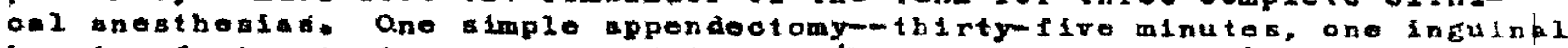
horbin--iorty minuter, and one fat lady (her tonth operation) for the remoral of gali bladdor, reviously dratned, and the repalr ot redirent Inguinal bernia, the iater operation lating one hour ond twenty-etght minuto:. An atiempt to use tho tank again this morning gave me an incuoliba but during the fineertion of the pheryageal airway, the small bmount of ojolopropano wa loat so that the one dog aneathosia and three cilntoal were all $l$ oquld sooure from tengalions.

The ofil bledier outse deforibed aboro was distinctiy Obeat, und of tho type most diffioult to rolax with any ottor mothod

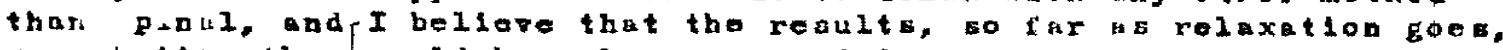
rero better than oould have been wooured in any othor way then spinal. Whother 1t who a good o wo would have aecurod with splnal, I doubl.

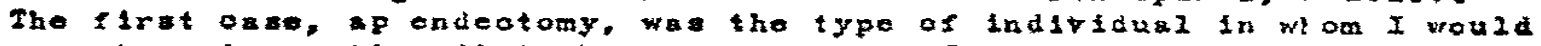
axpeat poetoporat 17e disturbanoos, yonng Jorest, who had had some vomiting provious to operation. She vomitod moro than we would hats

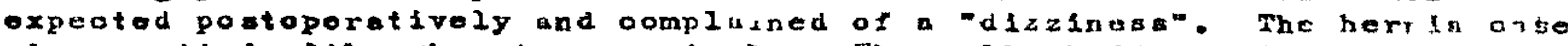
als ropited although not oxoessiraly. Tho gall bladdor and hornia wero dono this morning.

The blood preseure valiatione ata result of this agent

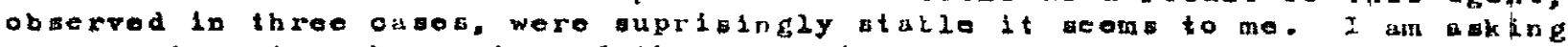
my socrotary to muke coples of the operating room oharts af these three oake for your information. Tho pulso rate in tho first ous was quita ristable, but was axtremely rapid bafore the onesthesia was begun due,

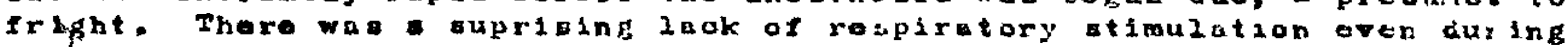
inoliotion in tho flrot osoo hnd wo thoreforo didn't inaert tho soda link during indiotton in tho other two. Tha pulae in ouch ouge thowed w lagh irrogularity when too graut a conoontation was reached. to arhythmis, but the arhythmia was used by no us an indiontion for more oxygen. Ha made gas analyaes of tho oxygen-oarbon dioxiae oontont of bat

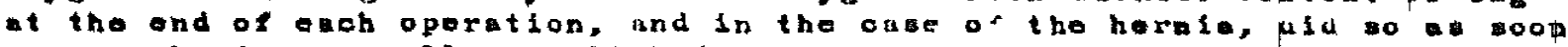

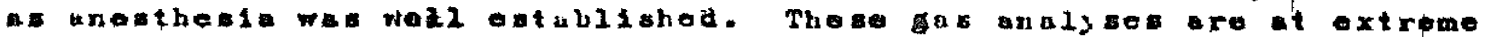

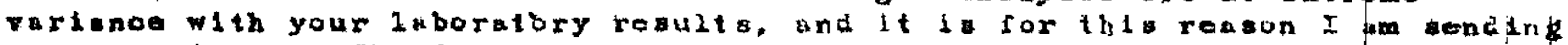
you thon todag. The firgt two ossea, as you will see, were run on perm

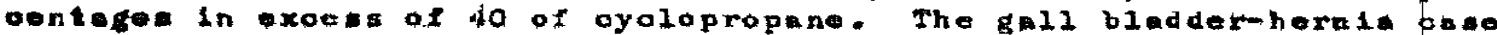

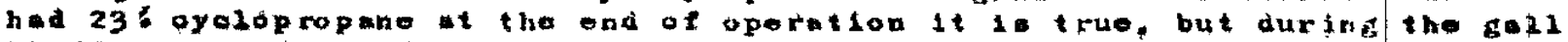

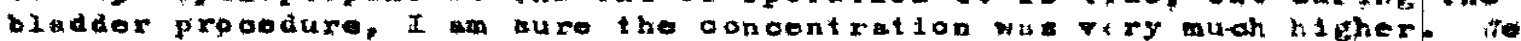
- aluted thet b 50-50 mixture was placod in the bag at the betinning and

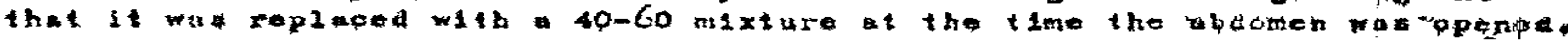

I IGUne 1 Facsimile of a letter from Dr Ralph Waters t Profeubor $V$ E Henderson concernng the first use cf cyclopropane in Lh hical surgery 


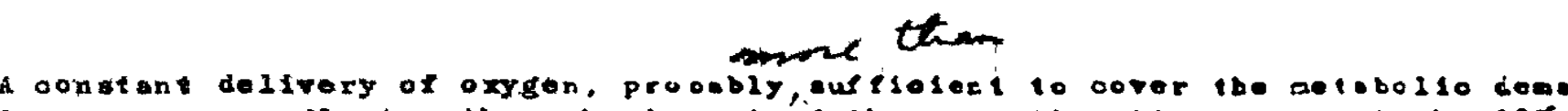

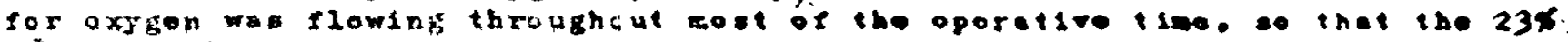
found in the bag at the ond of th hernla pperetied wee probebly muct. weaker then that used at the height of toe opereiso proaedure. I ghell te thed to

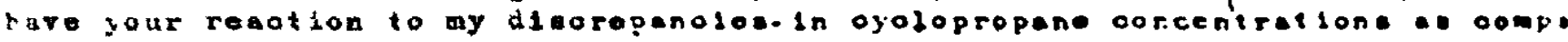

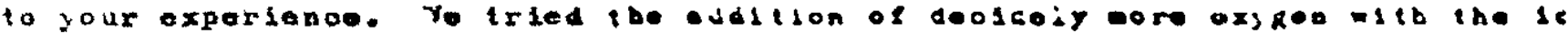

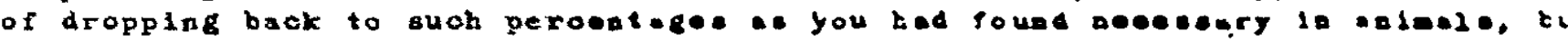

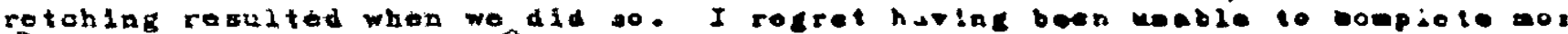

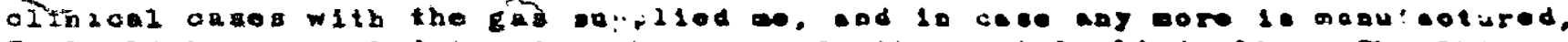

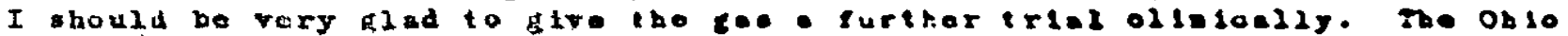

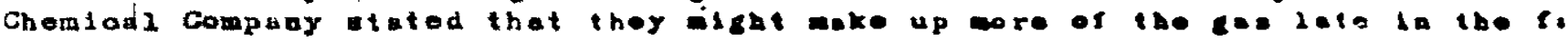

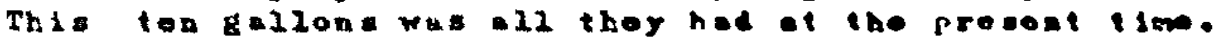

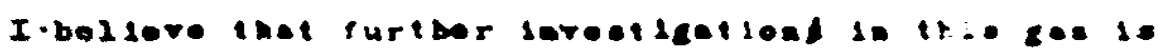

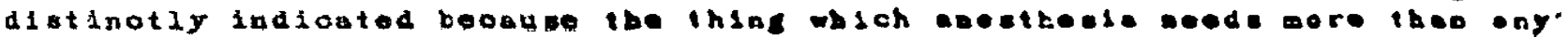

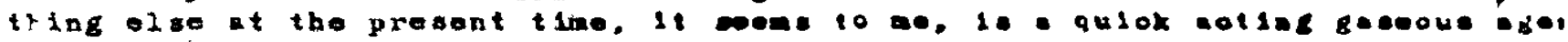

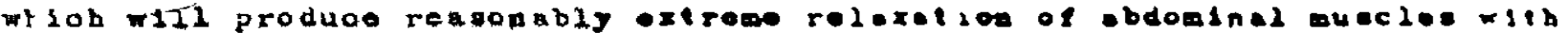
recsonably rapid lecorary therefrom. Tole, le ecee to e0, ejelepropene shows some posible oridenoe of doinc.

rrustiac ind ay notos mey bo os ane inicroet io you, and with kindest persongl regarde. I e.

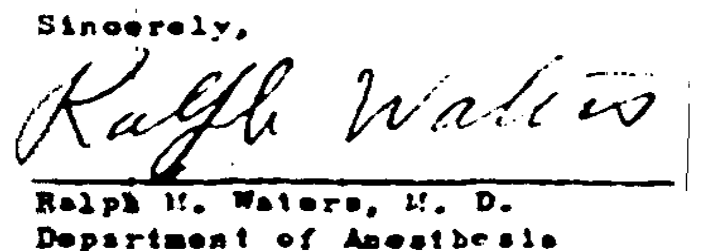

IMI $1: T+H$ 


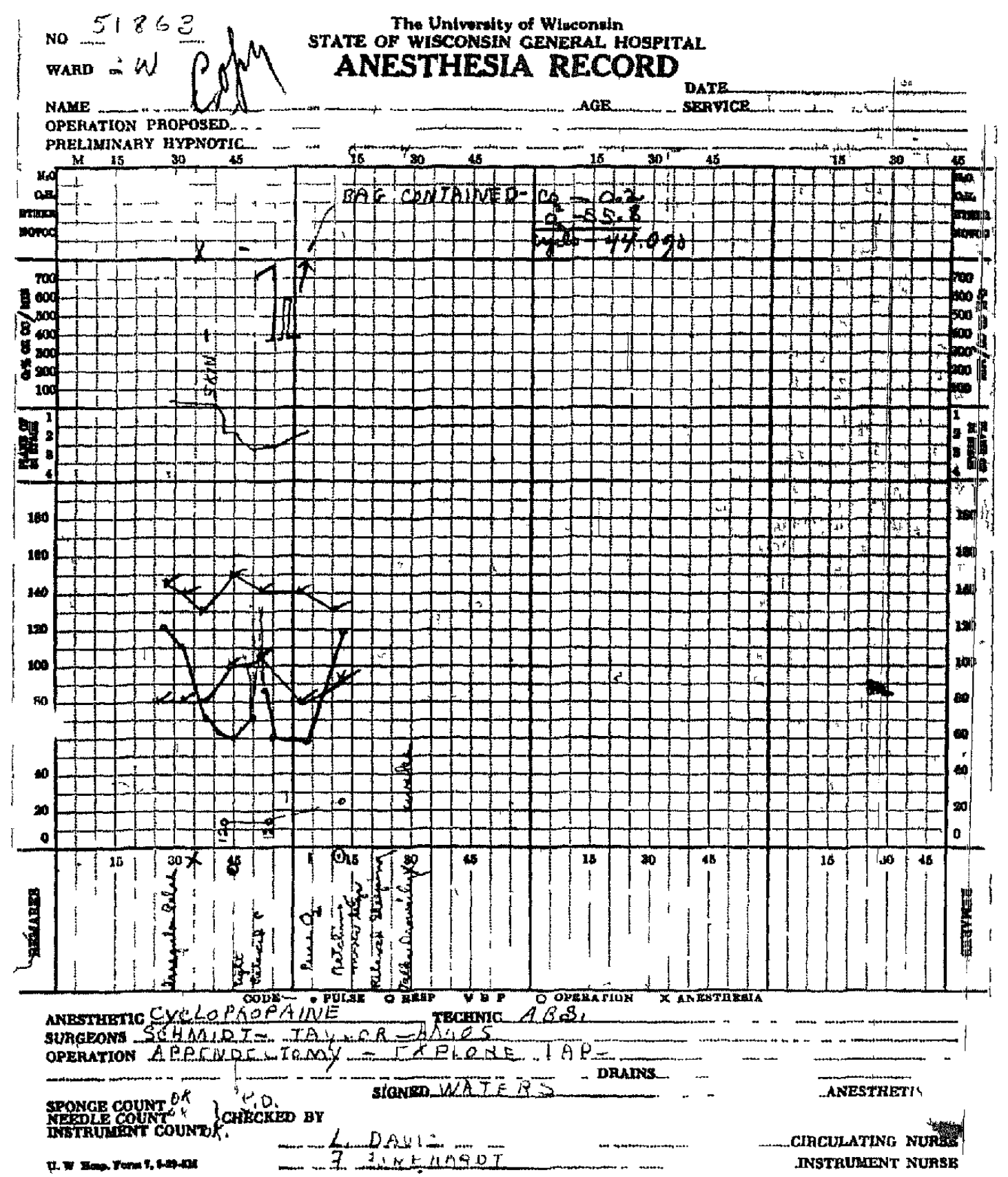

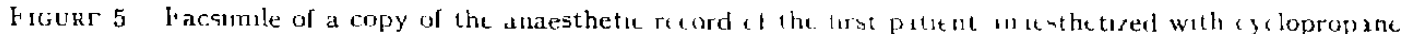
for a surgical operation supplied b) Dr it iters to Prolensor lle adtason 
PREOPBRATIVE-NOTES

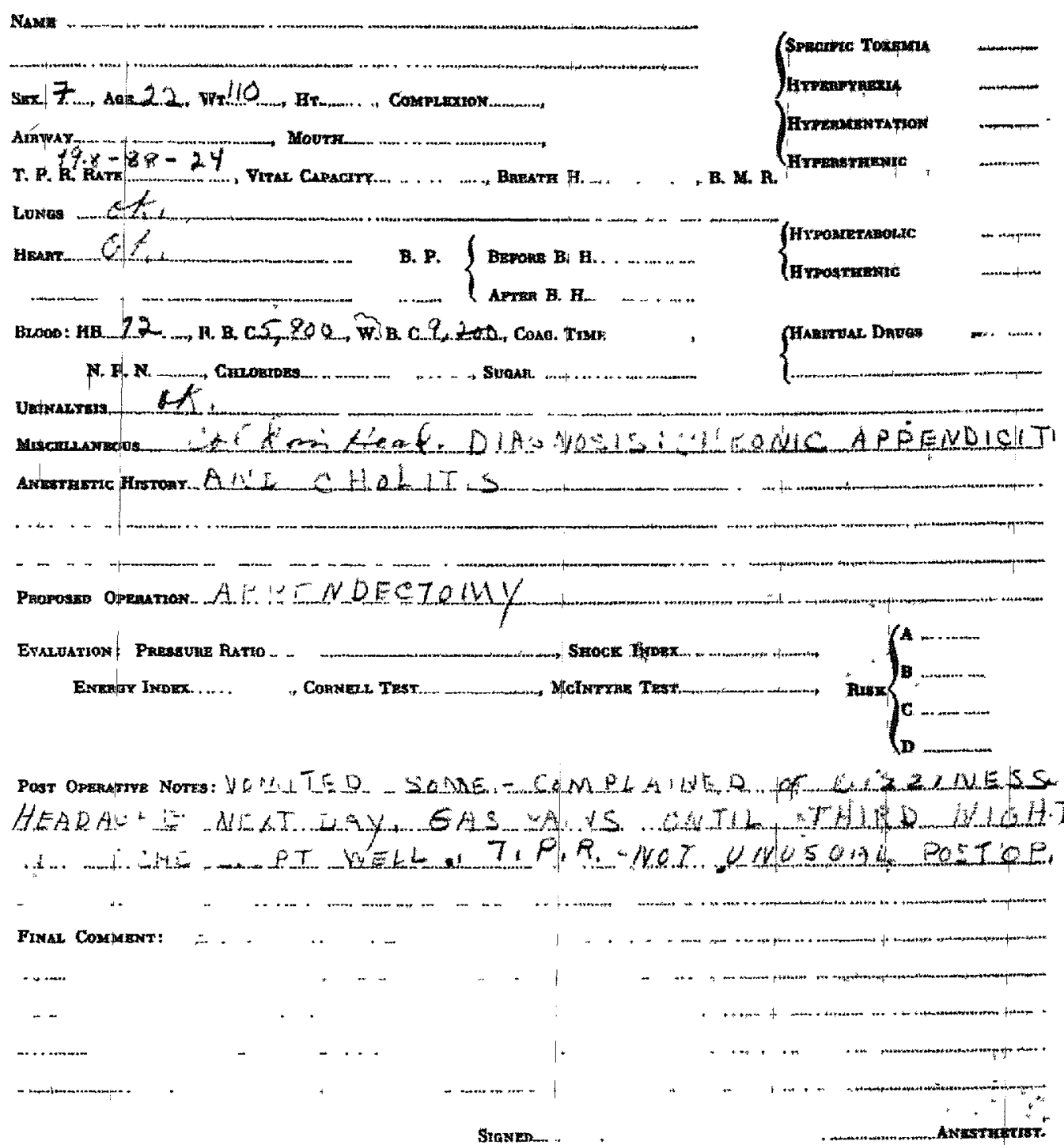

FIGURE 5 (cointinued) 


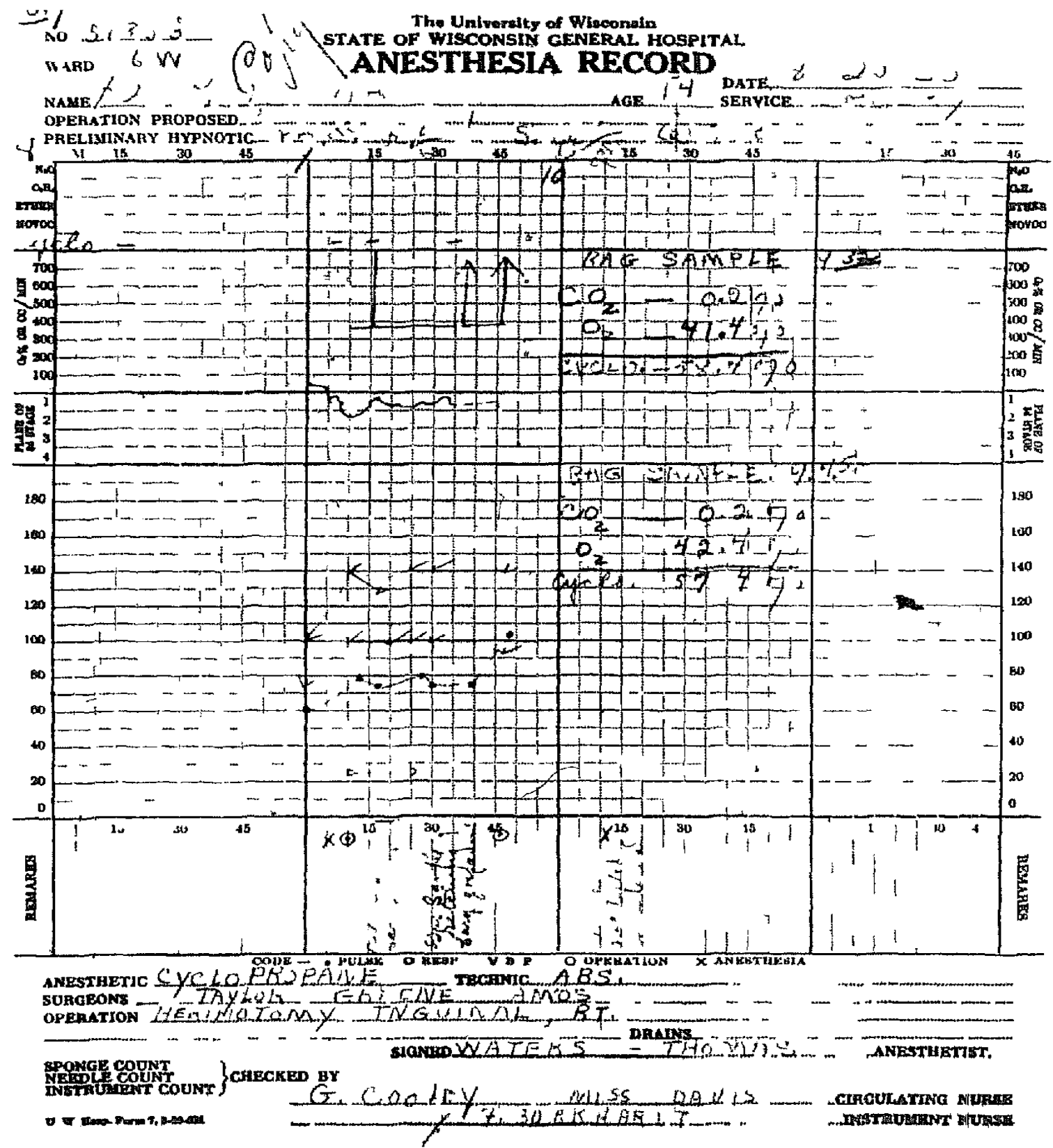

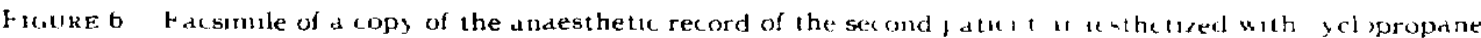
for a surgical operation supplied by Dr Waters to Profesom lletiderse 
PREOPERATIVE NOTTES

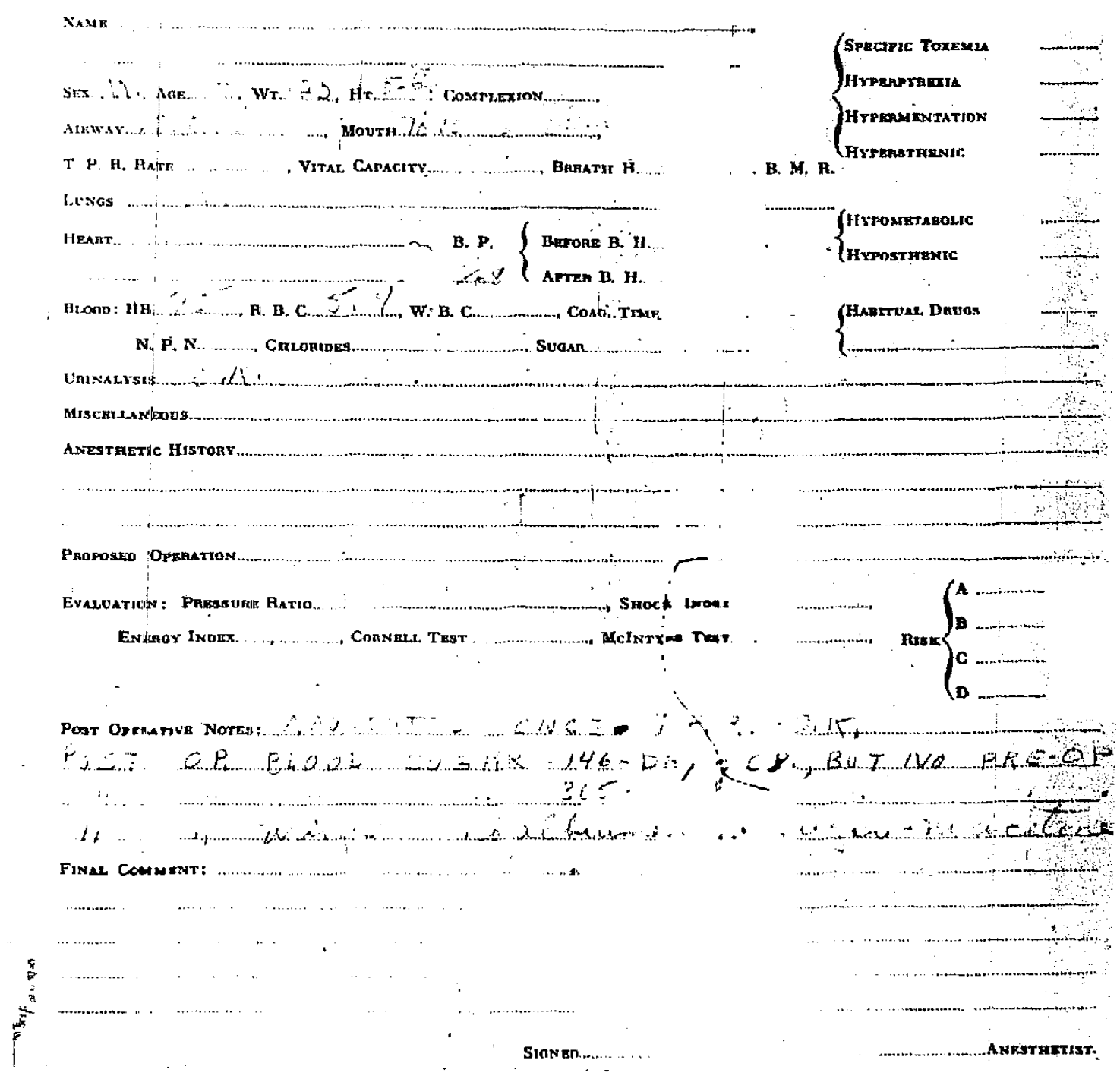

Jifi:al: b (ronlinued) 


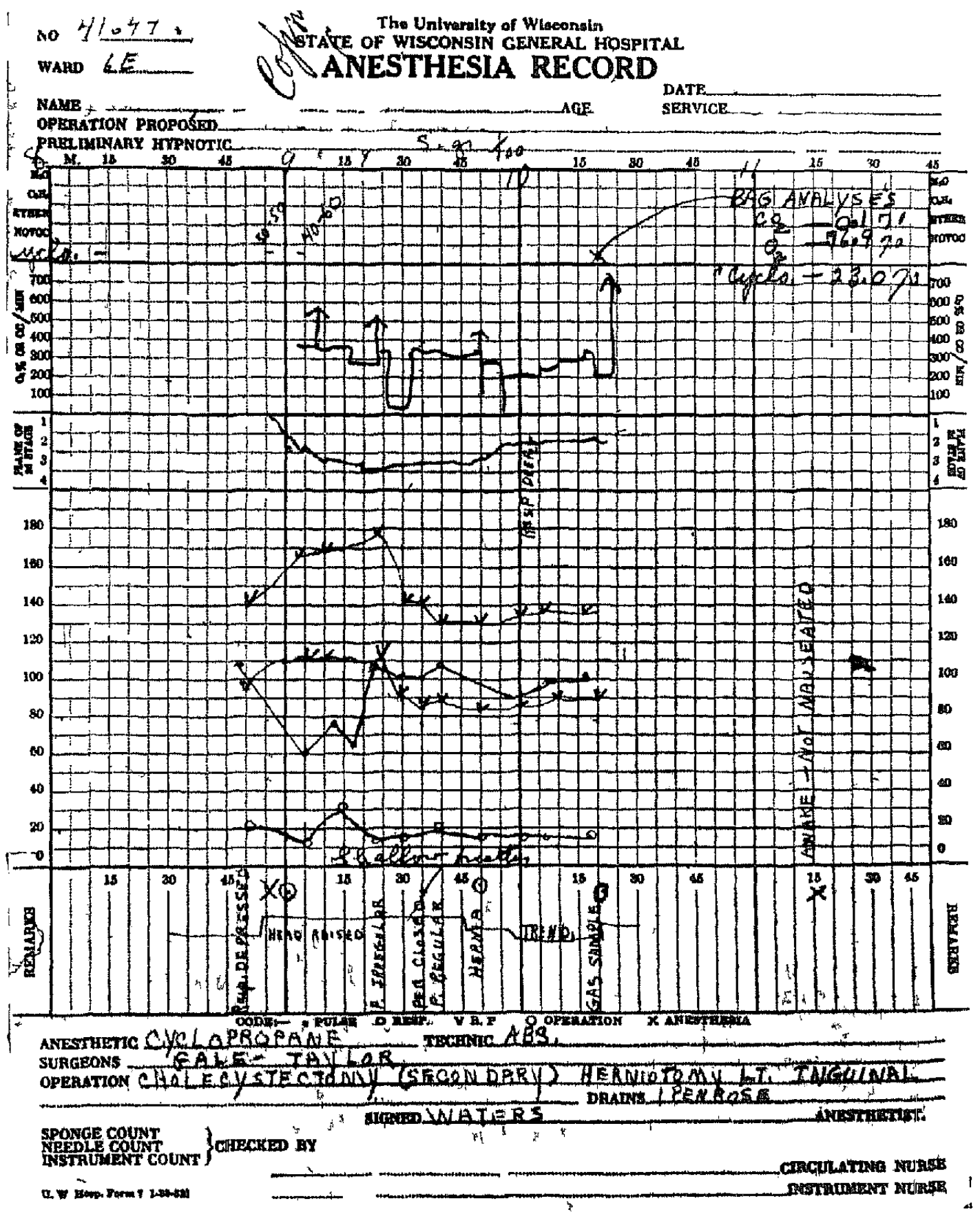

Figure 7 lacs n le of a itsthet c record of the third p t nt $1 \quad 1 \times$ th 11 i $11 \mid 1$ Dr Waters to $1 \mathrm{r}$ fess r He dicrso 
PREOPERATIVE NOMES

NXM:

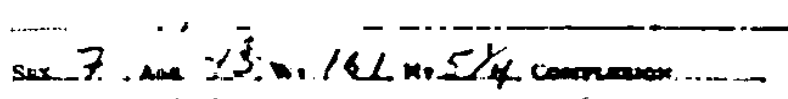

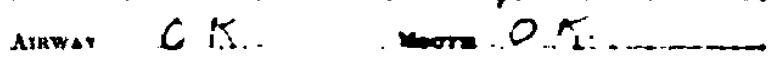

T. P. R Raik

vrec canars.

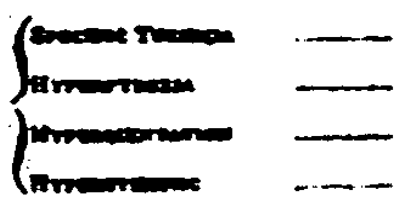

Luwor Gid:L

Hease - Qti...

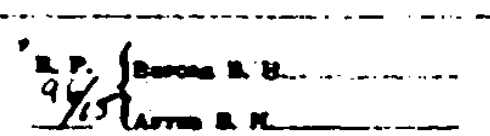

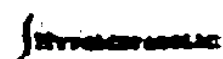

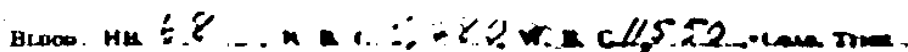

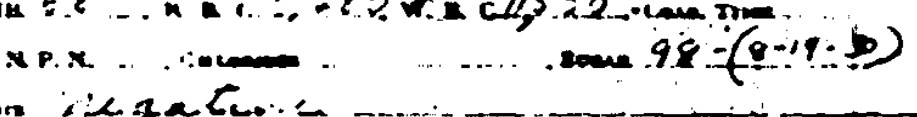

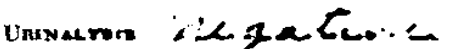

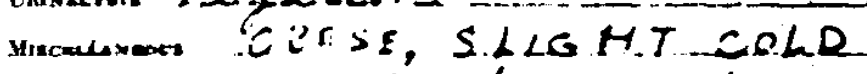

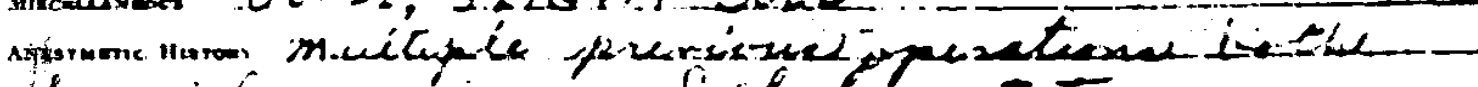

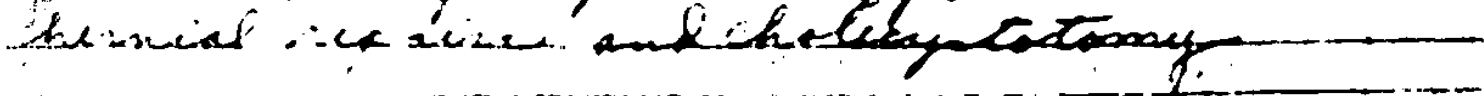

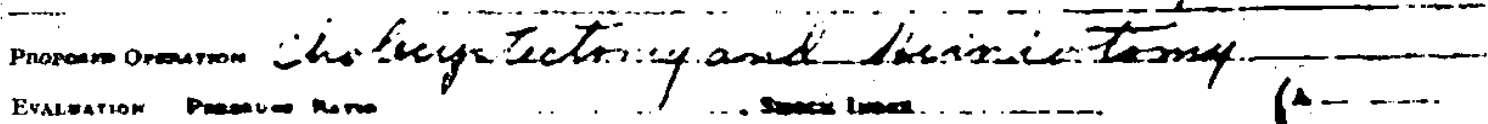

Pareand ipton

conven Tart

Mcimrim nax. ..

$$
\operatorname{nos}\left\{\begin{array}{l}
1 \ldots \ldots \\
\ldots \ldots \\
c \ldots \ldots
\end{array}\right.
$$

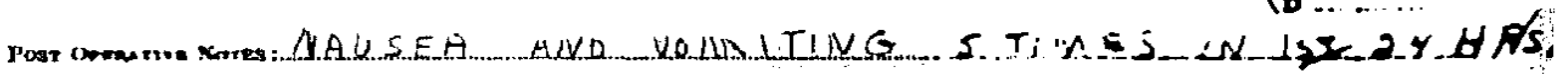

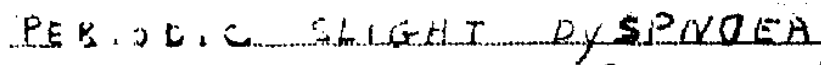

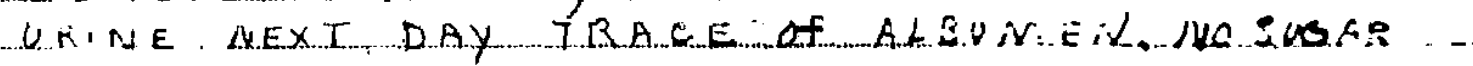
NOR. ACETRUE

Finat Com Dorme 
else at the present time, it seems to me, is a quick-acting gaseous agent which will produce reasonable extreme relaxation of the abdominal muscles with reasonably rapid recovery therefrom. This, it seems to me, cyclopropane shows some possible evidence of doing."

Professor Henderson, in answer to this letter, wrote (Fig. 8) pointing out that Dr. Waters should estimate the cyclopropane content of gaseous mixtures by dissolving it in sulphuric acid and should not assume that all the gas remaining after the removal of oxygen and carbon dioxide was cyclopropane (Fig. 5). I recall that Dr. Waters reported later that the analyses made by the Toronto method showed that the anaesthetic concentrations of cyclopropane were about half that reported in his first three cases.

The friendship, interest, and co-operation of two doctors outside of Toronto were largely responsible for the employment of cyclopropane clinically. Dr. Ralph M. Waters and Dr Harold R. Griffith were present in Montreal at the meeting of the Canadian Medical Association in June, 1929, when Professor Henderson announced our discovery of cyclopropane as a general anaesthetic. They were much interested in the gas and followed our p:ogress with it. Dr. Griffith became interested in Dr. Waters' success in the Wisconsin General Hospital and a paper presented by Stiles, Neff, Rovenstine, and Waters at the 12th Annual Congress of Anaesthetists in Chicago, October, 1933 (12), convinced him of its clinical value and led him to begin using it as a general anaesthetic in the Homeopathic Hospital of Montreal in 1933. He thus became the first anaesthetist in Canada to employ cyclopropane.

\section{Pharmacology of Cyclopropane}

Cyclopropane (trimethylene) was prepared in 1882 by Von Freund. It was made from trimethylene bromide plus zinc dust. Later it was made from 1 -3dichlorpropane plus zinc. This latter method is known as the Haas method. The anaesthetic potency of cyclopropane was determined in 1928-9 by Lucas and Henderson (10). Its molecular weight is 42.05 ; its specific gravity 1.46 (air-1). It liquefies at $\mathbf{5}$ atmospheres pressure at room temperature; the boiling point is $-34.4^{\circ} \mathrm{C}$. It is rapidly absorbed by sulphuric acid, a property which makes it easy to analyse when in combination with other gases. It is stable when stored in liquid form in steel alloy tanks at room temperature. The impurities occurring in it may be propylene, propane, allene, organic halides, and cyclohexane. Some of these are formed during its manufacture. The solubility in oil as compared to water is 34.4 ; oil as compared to blond 15.3. The flash point of this material is below $0^{\circ} \mathrm{C}$. The minimum ignition temperature is $927^{\circ} \mathrm{F}$. in air and $849^{\circ} \mathrm{F}$. in oxygen.

It is a colourless gas, non-irritating to the respiratory tract. It has a sweetish odour and taste. It is inflammable and, according to my notes, forms an explosive mixture in anaesthetic concentrations (Fig. 9); in air, mixtures of 2.4 to 10.3 per cent and oxygen 2.5 to 60 per cent are explosive. It is not altered in the body. The major portion is eliminated from the body in $10 \mathrm{~min}$., but for complete desaturation of the tissues a number of hours are required. No histological changes occur in any of the organs. 
Dr.R.H. Wabere.

Dept. of Anestheria.

State of Pisconsin Ceneral Hoepital. Hadion. Wis.

Daar Dr. Faters:

I an sorry to have dolaged in soknowlodging your lotter of lucust 20th, which oume wh1le I wag away on holidnys, and not eas liy reached.

Your exporience is extremely intelesting and viluable to ta. Or oxjeriments with the human anesthotica bave not progeded viry far, owine to varlous belaya und holidigs. Conse-

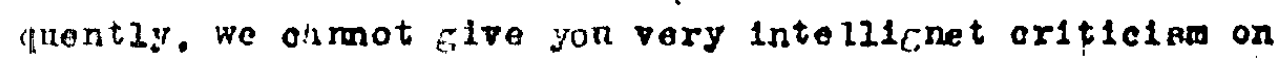
lour find inio. To are. howoror, oxtremely doubleul if buch a hich peroentajeo are requjred.

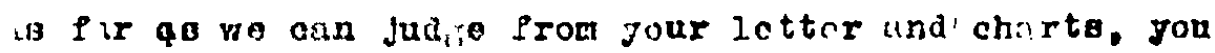
sstimale the amount of eyclopropane by annlyzini for oxysien fund cirbondbxide and oneiderine the residuc of cyclopropine. Wo are quito sure thet thil w11 not tito jou acourair rcoults. any Eils unalsoorbablo by pyrorallol will then be oounterd cjelopropane. Cyelopropane oux be abeorbed by otronge eulphurio nold. Hnd all our caloulations of anestretle concentrition have beon based on ouch an analyola: Fo find in one sumple of cyclovropane a conelderable amount of unabsorbublo kim. os ther a anturated hydrocarbon which 10 apt to be "rorsnt in armal smountis, or nitrogen.

We will let you know when we have tried some more exporinents. Youra olnoore 1 y. 


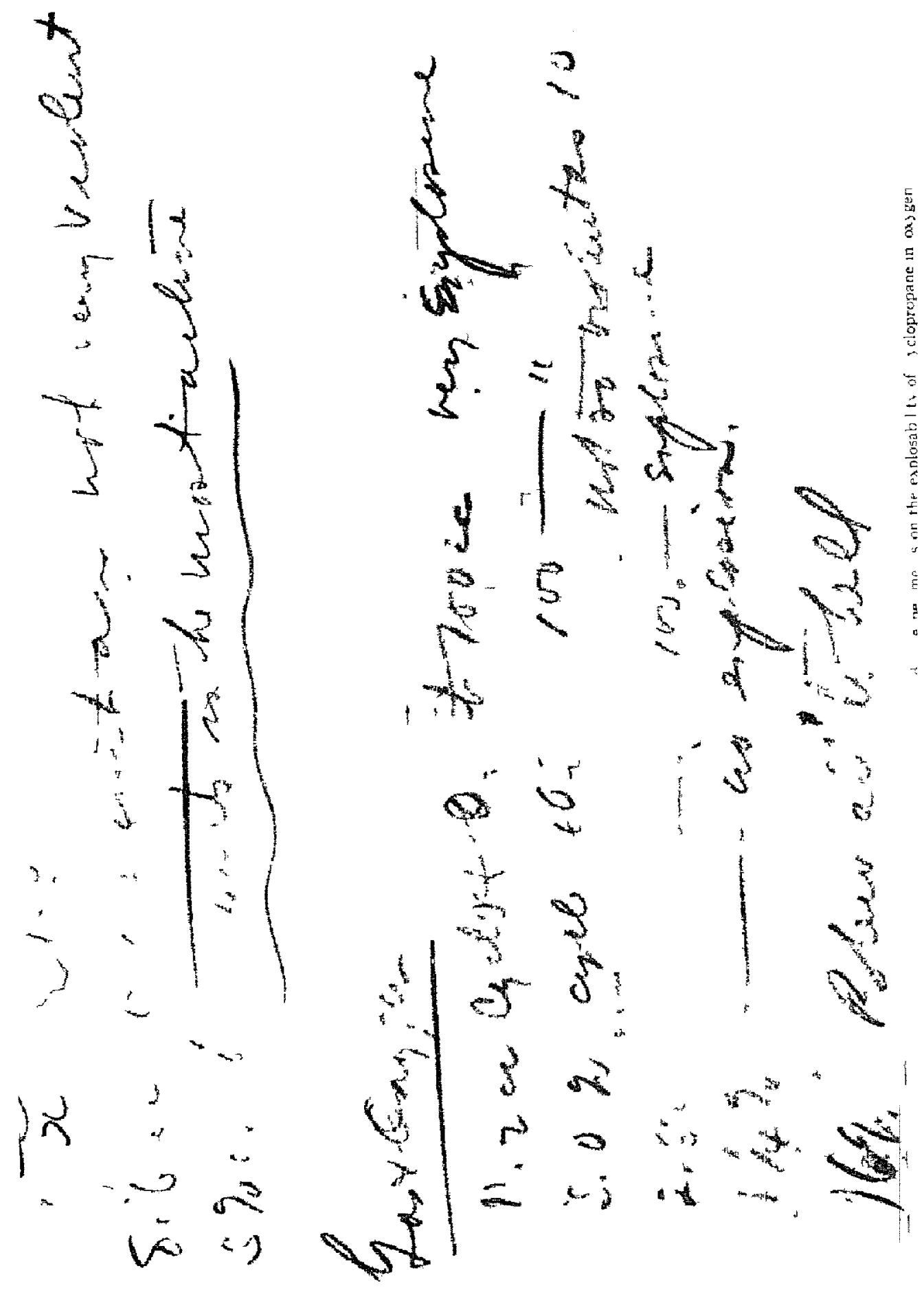


On inhalation laryngospasm may develop during induction or during very light anaesthesia, possibly owing to the parasympathomimetic action of the gas; atropine and scopolamine medication ordinarily inhibit this effect. Laryngospasm may occur if high concentrations are inhaled.

During cyclopropane anaesthesia, dreams do not occur as they do when nitrous oxide or ethylene is administered.

Analgesia occurs when concentrations of 3 per cent to 5 per cent of the gas are inhaled. Plane II requires from 11 to 14 per cent; plane III, 14 to 23 per cent; plane IV, 23 to 40 per cent. At this high, concentration respiration may fail. The gas is administered in a closed circuit and is not altered by alkaline absorbants or carbon dioxide. The kidneys, liver, spleen, and uterus are little affected during anaesthesia. The activity of the intestine is depressed in deep anaesthesia, but recovery is rapid when the gas is withdrawn. Blood-clatting time is unchanged although oozing and capillary bleeding are encountered owing to vasodilation and to some elevation of the blood pressure. Metabolic processes and blood chemical patterns are not disturbed significantly.

Relaxation of skeletal muscle is adequate for many surgical operations. The gas may be administered with muscle relaxants such as curare to gain greater relaxation.

The most serious disadvantage of cyclopropane lies in the fact that the irritability of the automatic tissue of the heart is increased, causing arrythmias from the displaced pacemaker. Vagus escape, atrioventricialar block, ventricular tachycardia, and ventricular fibrillation may occur spontaneously. The mechanism by which this anaesthetic adversely influences cardiac automaticity is not completely understood, although much research has been directed to the solution of the problem and a voluminous literature exists. There is some evidence that sympathetic reflexes arising in abdominal receptors play a. role in the production of these cardiac disorders.

It has been known for a long time that epinephrine and some related amines enhance the production of the arrythmias, but the mechanisms involved are subject to much debate. In the opinion of some worker's both the rise in blood pressure and the direct effect of epinephrine must be considered.

Epinephrine is lost from the adrenal gland during cyclopropane anaesthesia but less so than with ether. Ether, however, protects the heart from cyclopropane arrythmias when it is administered with the gas.

The proper choice of drugs for premedication may play an important role in the incidence of cyclopropane arrhythmias. There is some support for the belief that they arise more frequently with morphine than with barbiturates. The content of potassium in the myocardium may also play some role in the occurrence of arrhythmias in cyclopropane anaesthesia. It has been shown that an increase of the potassium in the myocardium follows the injection of epinephrine. Anoxia, an excessive rise in carbon dioxide, alkalosis, and a rise in blood sugar may also contribute to such irregularities.

Atalectasis, partial or massive, may occur, it is claimed, if the anaesthetist does not watch his patient carefully to be sure of adequate respiration and to see that some inert gas such as nitrogen or helium is left in the inspired air after cessation 
of the operation. Cyclopropane and oxygen are rapidly absorbed and unless some less soluble gas is in the lungs, areas may collapse.

Following long operations, postoperative hyppotension may occur (cyclopropañe shock). This condition appears to be associated with a severe respiratory acidosis. It is believed that the proper prophylaxis to prevent this syndrome may be achieved by maintenance of a normal alveolar carbon dioxide tension.

Experimentally on dogs, employing the cyclopropane-epinephrine test, investigators have reported that procaine amide, procaine, meperidine, quinidine, atropine (large doses), ergotamine, dibenamine, and tolazoline afford partial or complete protection against cardiac arrhythmias.

I have taken considerable time to discuss the early history of the research on anaesthesia in the Department of Pharmacology and to show how the pioneer investigations of the late Dr. Velyien E. Henderson and the late Dr. W. Easson Brown led to our discovery of cyclopropane. It was my good fortune to be associated with them in this work.

It is fortunate, also, that my notes on the preparation and first use of the gas experimentally on animals have been preserved, together with some of the apparatus used in the experimental investigations, and that I found Dr. Waters' letter to Professor Henderson, along with copies of the hospital records of Dr. Waters' three patients, and the copy of Dr. Henderson's reply.

\section{REFERENCES}

1. Brown, W. E. Canad.M.A.J. 13: 210 (1923).

2. Luctrhard, A. B., \& CARTER, J. B. J.A.M.A. 80: 765.(1923).

3. Brown, W. E. J. Pharmacol. \& Exper. Therap. 23: 485 (1924).

4. Bonham, L. J. J. Am. Pharmacol. Assoc. 14: 114. (1925).

5. Bert, P. Compt. rend. Acad. Sci. 88: 728 (1878); $89: 132$ (1879).

6. Brown, W. E., Lucas, G. H. W., \& Henderson, V. E. J. Pharmacol. \& Exper. Therap. $31: 269(1927)$.

7. Henderson, V. E., \& Lucas, G. H. W. Arch. Internat. Pharmacodyn. $97: 155$ (1930).

8. Henderson, V. E. Arch. Internat. Pharmacodyn. 98 : 149 (1930).

9. LuCas, G. H. W., \& Henderson, V. E. Canad.M.A.]. $21: 173$ (1929).

10. Henderson, V. E., \& LuCAs, G. H. W. Anesth. \& Analg. 9: 1 (1930).

11. Henderson, V. E., \& Simith, A. H. R. J. Pharmacol. \& Exper. Therap. 58: 319 (1936).

12. Stiles, J. A.; Neff, W. B.; Rovenstine, E. A.; \& Waters, R. M. Anesth. \& Analg. 13: 56 (1934). 